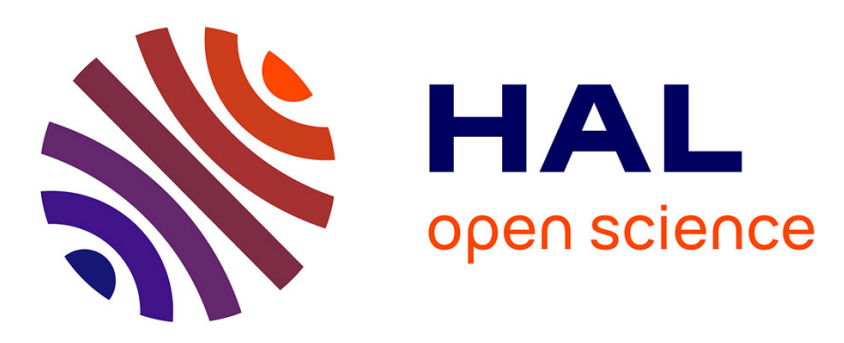

\title{
Atomic-scale computer simulation study of the interaction of Cu-rich precipitates with irradiation-produced defects in $\alpha$-Fe
}

Alan Christy Arokiam, Alexander V Barashev, David John Bacon, Yuri Osetsky

\section{To cite this version:}

Alan Christy Arokiam, Alexander V Barashev, David John Bacon, Yuri Osetsky. Atomic-scale computer simulation study of the interaction of $\mathrm{Cu}$-rich precipitates with irradiation-produced defects in $\alpha$-Fe. Philosophical Magazine, 2007, 87 (06), pp.925-943. 10.1080/14786430601003908 . hal00513778

\section{HAL Id: hal-00513778 \\ https://hal.science/hal-00513778}

Submitted on 1 Sep 2010

HAL is a multi-disciplinary open access archive for the deposit and dissemination of scientific research documents, whether they are published or not. The documents may come from teaching and research institutions in France or abroad, or from public or private research centers.
L'archive ouverte pluridisciplinaire HAL, est destinée au dépôt et à la diffusion de documents scientifiques de niveau recherche, publiés ou non, émanant des établissements d'enseignement et de recherche français ou étrangers, des laboratoires publics ou privés. 


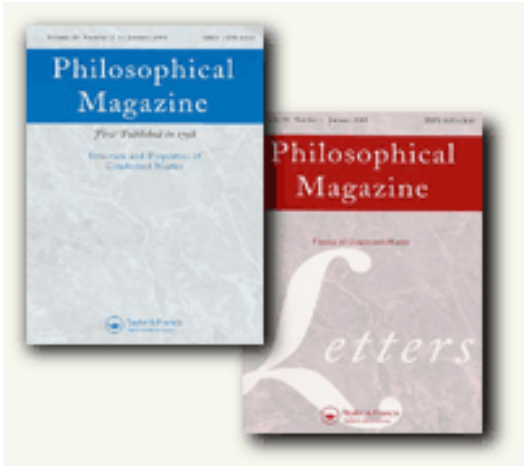

\section{Atomic-scale computer simulation study of the interaction of $\mathrm{Cu}$-rich precipitates with irradiation-produced defects in a-Fe}

\begin{tabular}{|c|c|}
\hline Journal: & Philosophical Magazine \& Philosophical Magazine Letters \\
\hline Manuscript ID: & TPHM-06-May-0142.R1 \\
\hline Journal Selection: & Philosophical Magazine \\
\hline $\begin{array}{r}\text { Date Submitted by the } \\
\text { Author: }\end{array}$ & 10-Sep-2006 \\
\hline Complete List of Authors: & $\begin{array}{l}\text { Arokiam, Alan; The University of Liverpool, Department of } \\
\text { Engineering } \\
\text { Barashev, Alexander; The University of Liverpool, Department of } \\
\text { Engineering } \\
\text { Bacon, David; University of Liverpool, Engineering } \\
\text { Osetsky, Yuri; Oak Ridge National Laboratory, Computer Science } \\
\text { and Mathematics Division }\end{array}$ \\
\hline Keywords: & Fe-based alloys, radiation damage, steel \\
\hline Keywords (user supplied): & copper precipitates, self-interstitial atoms \\
\hline
\end{tabular}

\section{scholarONE" \\ Manuscript Central}




\title{
Atomic-scale computer simulation study of the interaction of $\mathrm{Cu}$-rich precipitates with irradiation-produced defects in $\alpha-F e$
}

\author{
A. C. AROKIAM*†, A. V. BARASHEV $\uparrow$, D. J. BACON $\dagger$ and Yu. N. OSETSKY $\dagger$ \\ $\dagger$ Department of Engineering, The University of Liverpool, Brownlow Hill, \\ Liverpool L69 3GH, UK \\ †Computer Science and Mathematics Division, ORNL, Oak Ridge, \\ TN 37831-6138, USA
}

\begin{abstract}
Copper-rich precipitates can nucleate and grow in ferritic steels containing small amounts of copper in solution and this affects mechanical properties. Growth kinetics, composition and structure of precipitates under irradiation are different from those under thermal ageing, and also vary with type of radiation. This implies that the interaction between radiation defects, i.e. vacancies, self-interstitial atoms (SIAs) and their clusters, and precipitates is influential. It is studied here by atomic-scale computer simulation. The results are compared with those of elasticity theory based on the size misfit of precipitates and defects, and the modulus difference between bcc iron and bcc copper. It is found that SIA defects are repelled by precipitates at large distance but, like vacancies, attracted at small distance. Copper precipitates in iron can therefore be sinks for both vacancy and interstitial defects and hence can act as recombination centres under irradiation conditions. A tentative explanation for the mixed $\mathrm{Cu}-\mathrm{Fe}$ structure of precipitates observed in experiment and the absence of precipitate growth under neutron irradiation is given. More generally, agreement between the simulations and elasticity theory suggests that the results are not artefacts of the atomic model: both vacancy and interstitial defects in metals may bind to precipitates with weaker cohesion than the matrix.
\end{abstract}

Key words: Iron alloys, ferritic steels, radiation damage, copper precipitates, self-interstitial atoms

*Author for correspondence. Email: alanca@liverpool.ac.uk 


\section{Introduction}

Reactor pressure vessel (RPV) steels in nuclear plant are exposed to neutron irradiation at temperature $\sim 270-300^{\circ} \mathrm{C}$. The radiation creates damage in the form of point defects and their clusters, which are mobile at the temperature of operation, leading to further microstructure modification. In steels containing copper $(\mathrm{Cu})$ in solution, which is at significant levels $\sim 0.4 \mathrm{wt} \%$ in older plant [1], Cu-rich precipitates also form. The increase in yield stress and reduction of ductility that occur in service [2] arise from the interaction of dislocations with both the point defect 'matrix' damage and the $\mathrm{Cu}$ precipitates. Because of the potential importance of these effects, many experiments have been undertaken to study precipitate evolution and structure in $\mathrm{Fe}-\mathrm{Cu}$ alloys after either thermal ageing, electron irradiation or neutron irradiation.

Thermal ageing provides conditions where the only mechanism involved in $\mathrm{Cu}$ transport in the $\alpha$-iron (Fe) matrix is due to vacancies. Precipitates nucleate, grow and coarsen $[3,4]$ and are practically pure copper at least for the precipitate size greater than $2 \mathrm{~nm}$ diameter $[4,5]$. They have bcc crystal structure coherent with the matrix when small, but with increasing size $\left(\sim 12 \mathrm{~nm}\right.$ at $550^{\circ} \mathrm{C}$ and $\sim 4 \mathrm{~nm}$ when cooled down to room temperature) lose coherency and transform towards the stable fcc crystal structure through two intermediate structures $9 \mathrm{R}$ and $3 \mathrm{R}$ [6]. As a result the level of hardening passes through a maximum and then decreases. Computer simulation and other evidence show that strong pinning of dislocations by small precipitates is due to dislocation-induced transformation of precipitates from bcc to faulted fcc [7,8]. Electron irradiation produces damage in the form of single vacancies and self-interstitial atoms (SIAs), and the main effect is to enhance the diffusion of $\mathrm{Cu}$ atoms by the super-saturation of vacancies and, hence, to accelerate the precipitation kinetics $[5,9,10]$. As in thermal ageing conditions, the precipitates grow to relatively large size (up to $\sim 17 \mathrm{~nm}$ diameter) and exhibit phase transformation towards fcc structure at size above $4-8 \mathrm{~nm}[9]$.

Precipitation in neutron-irradiated ferritic steel is different to that under either thermal ageing or electron irradiation. At temperature less than about $300^{\circ} \mathrm{C}$, precipitates do not coarsen to diameter greater than $\sim 4 \mathrm{~nm}$ in binary $\mathrm{Fe}-\mathrm{Cu}$ alloys [11] and are even smaller $(\sim 2$ $\mathrm{nm})$ in ferritic pressure-vessel steels [12,13]. The hardness increase due to precipitates is therefore close to a maximum. Furthermore, precipitate $\mathrm{Cu}$ content varying from 45 to 95 at $\%$ has been reported [14] and the size at which precipitates lose coherency is considerably smaller than in thermally-aged alloys [11]. Despite many experimental and theoretical 
studies, considerable uncertainty remains about the mechanisms of precipitation and associated hardening in neutron-irradiated ferritic steels containing copper.

Theoretical treatments of precipitation assume homogeneous nucleation and growth due to migration of $\mathrm{Cu}$ atoms via the vacancy mechanism [5,15-18], with acceleration due to irradiation accounted for by rescaling the time (see e.g. [17,18]). Such an approach may be appropriate for electron irradiation. For neutron or heavy ion irradiation the situation is more complicated and requires a more sophisticated analysis, however. Indeed, computer simulation shows that $<111>$ SIA clusters are produced directly in the cascade process (e.g. [20]). They are highly mobile [21] and so may interact with precipitates. This has led to the suggestion that spatial correlation can exist between clusters and precipitates $[17,19]$, in which case precipitates could act as recombination regions for vacancies. A consequence would be that evaporation of $\mathrm{Cu}$ atoms from precipitates, and hence Oswald ripening, would be suppressed. It is important, therefore, to investigate the nature of the interaction of vacancies, single SIAs and SIA clusters with bec $\mathrm{Cu}$-rich precipitates in an $\alpha$-Fe matrix, and to assess whether SIA trapping and enhanced recombination due to precipitates is likely.

This was tackled in a recent Letter [22], in which atomic-scale computer simulation was used to study the spatial dependence of the interaction energy of a vacancy and a small SIA cluster with spherical pure $\mathrm{Cu}$ and $\mathrm{Cu}$-rich precipitates in $\mathrm{Fe}$. It was shown that although interstitial defects are repelled by precipitates at large distance due to their strain field, they can be attracted at distances of $\sim 1 \mathrm{~nm}$. It would seem, therefore, that copper precipitates in iron can be sinks for both vacancy and interstitial defects, and hence can act as recombination centres under cascade-damage conditions.

The present paper follows up the preliminary results in [22] with a more comprehensive set of simulations and analyses. We seek a plausible explanation for the observed mixed $\mathrm{Cu}-\mathrm{Fe}$ composition of precipitates, the absence of precipitate growth and other features of $\mathrm{Cu}$-precipitates in $\mathrm{Fe}-\mathrm{Cu}$ alloys under neutron irradiation conditions. The paper is organised as follows. The general calculation approach and the main ideas to be checked are described in section 2. Results are described in section 3. They include: molecular dynamics (MD) simulations of the interaction of migrating SIA clusters with isolated $\mathrm{Cu}$ atoms and precipitates in 3.1; molecular statics (MS) calculations, i.e. potential energy minimisation at $T=0 \mathrm{~K}$, of the interaction between precipitates and SIA clusters, performed to give insight into the MD results, in 3.2; and calculation of the same interactions by isotropic, linear elasticity theory, comparison with MS results and interpretation of the MD 
results in 3.3. In section 4 we draw conclusions and propose a tentative explanation of observed precipitation features under neutron-irradiation conditions.

\section{Simulation methods}

\subsection{Atomistic simulations}

MD was used to study dynamics of SIA clusters near $\mathrm{Cu}$-atoms and precipitates. Simulation boxes of cuboid shape with periodic boundary conditions along [111], [11 $\overline{2}]$ and [1 $\overline{1} 0]$ axes were used. Model size along [111] was 61 to $87 a_{0}$, where $a_{0}$ is the bcc lattice parameter of Fe $(0.2867 \mathrm{~nm}$ at $0 \mathrm{~K})$, and 13 to $37 a_{0}$ in the orthogonal [11 $]$ and [1 $\left.\overline{1} 0\right]$ directions, depending on precipitate and SIA cluster size. The corresponding number of lattice sites was 19,000 to 228,000 . Calculations were carried out for temperature, $T$, equal to $300 \mathrm{~K}, 600 \mathrm{~K}$ or $900 \mathrm{~K}$. The potential set for the Fe-Cu system developed by Ackland et al. [23] was used to describe interatomic interactions. The simulations were performed at zero-pressure as described in [24]. Integration of Newtonian equations of motion over time was performed using the velocity Verlet-leapfrog algorithm [25] with variable time-step, so that at each step the fastest atom in the system moved a maximum distance of 0.004 to $0.005 a_{0}$ depending on the temperature [26]. The corresponding average time-step was in the range from 0.6 to $1.3 \mathrm{fs}$. During simulations the position of the centre of mass of the SIA/SIA cluster was recorded.

Interaction energy, $E_{\mathrm{J}}$, of point defects (single vacancies and self-interstitial atoms) and SIA clusters with precipitates at $T=0 \mathrm{~K}$ and its dependence on precipitate size and composition, SIA cluster size and position near the precipitate was studied by MS. Simulations were performed using a simulation box of size 60,35 and $35 a_{0}$ along the [111], $[11 \overline{2}]$ and [1 $\overline{1} 0]$ directions, respectively, and containing 158,000 lattice sites. Periodic boundary conditions were applied along [111] and [11 $\overline{2}]$ and fixed boundary conditions along [1 $1 \overline{1} 0]$ direction. $E_{\mathrm{I}}$ was defined as the energy difference between systems of interacting and non-interacting defects: a negative sign corresponds to attraction.

Spherical, coherent precipitates were simulated in both MD and MS studies. Precipitates with radius, $R_{\mathrm{P}}$, between 0.29 and $2.5 \mathrm{~nm}$, i.e. containing 9 to 5601 atoms, and composition in the range 100 to $25 \mathrm{at} \% \mathrm{Cu}$ (balance $\mathrm{Fe}$ ) were modelled. 


\subsection{Continuum calculations}

The pressure field outside a misfitting spherical inclusion is zero in isotropic, linear elasticity theory. Thus, the vacancy-precipitate attraction is short-ranged in this theory and due to the different elastic constants of bcc $\mathrm{Cu}$ and $\mathrm{Fe}$ and, within the precipitate, to the difference in cohesive energy. This agrees with the calculations presented in figure 1 of [22].

With regard to SIAs, there does not appear to be published work treating the interaction between SIA clusters and precipitates in the framework of elasticity theory. There are two contributions to this interaction. First, an SIA cluster and a $\mathrm{Cu}$ precipitate are defects with positive dilatation in the iron matrix and so they interact with each other due to their elastic fields. The second contribution comes from the different elastic moduli of a bcc $\mathrm{Cu}$ precipitate and the surrounding Fe matrix. We now consider two simplified cases which can be treated analytically in linear isotropic elasticity. The first models a precipitate as a spherical centre of dilatation and the SIA cluster as a small dislocation loop. (Treating the SIA defect simply as another centre of dilatation would result in zero interaction.) The second takes the precipitate to be an inclusion with different elastic properties from the matrix and the SIA defect as an oversized spherical defect. Both are rather simple approximations, but will be seen to contain the essential physics underlying the contributions to the interaction found in the atomic simulations.

First, consider a precipitate to be a spherical inclusion of radius $R_{\mathrm{P}}$, which has the same elastic constants as the matrix but is a centre of positive dilatation. It is characterised by a misfit parameter $\varepsilon$, the relative difference of atomic spacing inside and outside the inclusion. In linear isotropic elasticity the inclusion creates radial displacement, $u$, at distance $r$ from the precipitate centre of the form:

$$
u=\frac{\varepsilon R_{\mathrm{P}}^{3}}{r^{2}}
$$

in the matrix and

$$
u=\varepsilon r
$$

within the inclusion. Outside the precipitate the radial component of the normal stress along an axis through the precipitate centre is given by 


$$
\sigma_{r r}=-4 G_{\mathrm{m}} \frac{\varepsilon R_{\mathrm{P}}^{3}}{r^{3}}
$$

where $G_{\mathrm{m}}$ is the shear modulus of the matrix. Finally, the interaction energy with an SIA cluster treated as an infinitesimal loop of area $A$ with Burgers vector $\boldsymbol{b}$ in the radial direction from the inclusion centre is given by

$$
E_{\mathrm{I}}=-\sigma_{r r} A b
$$

The most relevant solution for the modulus difference is that by Moon and Pao [28], who showed that the ratio of the shear moduli of the matrix, $G_{\mathrm{m}}$, and inclusion, $G_{\mathrm{P}}$, determines whether the interaction energy between a spherical inclusion (with $\varepsilon=0$ ) and a defect represented by a centre of dilatation is positive or negative. The interaction energy for an isotropic point defect of source strength $c$ at distance $r>R_{\mathrm{P}}$ from an inclusion in a matrix with Poisson ratio $v_{\mathrm{m}}$ is given by:

$$
E_{\mathrm{I}}=\frac{4 \pi\left(1-v_{\mathrm{m}}\right) c^{2} G_{\mathrm{m}}}{R_{\mathrm{P}}^{3}}\left[1-\frac{G_{\mathrm{m}}}{G_{\mathrm{P}}}\right] \sum_{n=0}^{\infty} \beta_{n}\left(\frac{R_{\mathrm{P}}}{r}\right)^{2 n+2},
$$

where

$$
\beta_{n}=\frac{n(n-1)(2 n-1)(2 n+1)}{(n-1)\left[(3 n+2)-2 v_{\mathrm{m}}(2 n+1)\right]+\left[n^{2}+n+1-v_{\mathrm{m}}(2 n+1)\right] G_{\mathrm{m}} / G_{\mathrm{P}}} .
$$

It follows that the interaction is negligible when $r>2 R_{\mathrm{P}}$ [28]. Note that equation (5) diverges at $r \rightarrow R_{\mathrm{P}}$, which is an artefact arising from imposition of displacement continuity boundary conditions at the surface of the inclusion. In the absence of a more rigorous treatment for an asymmetric defect, we use this equation for an interstitial loop with a suitable choice of $c$.

\section{Results}

\subsection{MD simulations}


The coherent bcc spherical precipitates were either pure $\mathrm{Cu}$ or had composition 75,50 or $25 \mathrm{at} \% \mathrm{Cu}$ (balance Fe) with atoms randomly distributed on the lattice sites. Single SIAs in $<111>$ crowdion or $<110>$ dumbbell configuration and clusters of regular hexagon shape containing seven SIAs (in crowdion configuration) were considered. The $<110>$ SIA has lower formation energy $(4.87 \mathrm{eV})$ than the $<111>$ defect $(5.00 \mathrm{eV})$ for the Fe potential used. The $<111>$ configuration is the most stable for a cluster of seven SIAs, and has some characteristics of a small dislocation loop with Burgers vector $\boldsymbol{b}=1 / 2<111>$ and glide prism with $\{110\}$ faces formed by the loop periphery and $\boldsymbol{b}$. It is glissile with high mobility along its glide prism [21].

We first consider results for the following initial configurations involving a 7-SIA cluster with [111] axis. (1) The cluster lies between two single $\mathrm{Cu}$ solute atoms in the [111] atomic row along the centre of its glide prism at $600 \mathrm{~K}$; (2) the two $\mathrm{Cu}$ atoms lie on a [111] atomic row immediately outside the glide prism at $300 \mathrm{~K}$; and (3) the $\mathrm{Cu}$ atoms in (1) are replaced by two pure $\mathrm{Cu}$ precipitates of radius $R_{\mathrm{P}}=0.55 \mathrm{~nm}(59 \mathrm{Cu}$ atoms $)$ at $600 \mathrm{~K}$. To minimise the interaction of the SIA cluster with both copper objects at the same time, the distance between them was taken to be $\sim 9 \mathrm{~nm}$, i.e. about $36 b$, and thus bigger than the effective cluster size of $\sim 3 \mathrm{~nm}$ along $\boldsymbol{b}$ [21]. The simulations ran for about 4 to $14 \mathrm{~ns}$ and the cluster position was recorded every fs.

The results are summarized in figure 1 by an updated version of figure 7 of [22]. It shows the fraction of time the SIA cluster spent in different positions along its [111] glide direction. The position of the copper obstacles is indicated. The data for case 1 reflect the repulsive interaction between the cluster and an oversized $\mathrm{Cu}$ atom within the glide prism. It is seen that the cluster spent little time near the $\mathrm{Cu}$ atoms compared to other regions. Case 2 shows the opposite behaviour. The cluster was clearly attracted to $\mathrm{Cu}$ atoms just outside the glide prism and spent most time in their vicinity, only occasionally breaking away from one and gliding towards the other. Finally, the results for case 3 when the SIA cluster was placed initially mid-way between two precipitates show that although it spent considerable time ( 230ps) moving back and forth between them, i.e. it experienced repulsion, it eventually moved inside one of them and was trapped there for the rest of the simulation. This is evidence of strong binding between an SIA cluster and a pure $\mathrm{Cu}$ precipitate.

[Insert figure 1 about here] 
For cases 1 and 2 involving single $\mathrm{Cu}$ atoms, the data were used to estimate the interaction energy, $E_{\mathrm{I}}$, between the cluster and a $\mathrm{Cu}$ atom using the Boltzmann distribution via the equation

$$
E_{\mathrm{I}}=k_{\mathrm{B}} T \ln \left(t_{\mathrm{away}} / t_{\mathrm{at}}\right)
$$

where $t_{\mathrm{at}}$ and $t_{\text {away }}$ are the fractional times the cluster spent near and away from $\mathrm{Cu}$ atoms, respectively, and $k_{\mathrm{B}}$ is the Boltzmann constant. For case (1) $t_{\mathrm{at}}$ was obtained from the average of the lowest value of the fractional time in the two troughs on the curve plotted in Figure 1. The values for the other times were estimated in a similar manner. They are $t_{\mathrm{at}}=$ 0.002 and $t_{\text {away }}=0.028$ for case 1 and $t_{\mathrm{at}}=0.007$ and $t_{\text {away }}=0.05$ for case 2 and $E_{\mathrm{I}}$ is about 0.14 and $-0.05 \mathrm{eV}$, respectively. These times are very approximate figures, but the energy is insensitive to these values because of the logarithmic dependency in equation (6). (The error estimated via the equation $\Delta E_{\mathrm{I}}=k_{\mathrm{B}} T \sqrt{\varepsilon_{\text {at }}^{2}+\varepsilon_{\text {away }}^{2}}$, where $\varepsilon_{\mathrm{at}}$ and $\varepsilon_{\text {away }}$ are the relative errors of $t_{\text {at }}$ and $t_{\text {away }}$, respectively, is about $0.02 \mathrm{eV}$ for both cases.) The cluster did not visit all possible positions in the simulation volume in case (3), and $E_{\mathrm{I}}$ cannot be determined from equation (6).

It is also instructive to mention some simulations of the 7-SIA loop with precipitates of different radius and composition. For the case 3 described above and $1 \mathrm{~nm}$ radius precipitates containing $25 \mathrm{at} \% \mathrm{Cu}$, penetration by the cluster took place at $426 \mathrm{ps}$ from the beginning of the simulation at $600 \mathrm{~K}$. For $0.78 \mathrm{~nm}$ radius precipitates containing $75 \mathrm{at} \% \mathrm{Cu}$, the penetration time was $147 \mathrm{ps}$. In both the cases, the cluster remained trapped inside the precipitate for the remainder of the simulation time of $\sim 4 \mathrm{~ns}$. For a pure $\mathrm{Cu}$ precipitate of 1 $\mathrm{nm}$ radius and those containing 75 and $50 \mathrm{at} \% \mathrm{Cu}$, simulations ran for $3.7 \mathrm{~ns}$, but no penetration was observed. A single dumbbell SIA created initially on the [111] axis in [1 $\overline{1} 0]$ orientation entered a pure $\mathrm{Cu}$ precipitate of $1 \mathrm{~nm}$ radius in $2.55 \mathrm{~ns}$. It is therefore concluded that the probability to penetrate the repulsive barrier is higher for smaller precipitates, lower $\mathrm{Cu}$ content and smaller SIA defects, which is the case under neutron or heavy ion irradiation.

We also studied interaction between a pure $0.55 \mathrm{~nm} \mathrm{Cu}$ precipitate at $900 \mathrm{~K}$ and two 7 SIA clusters at the same time. The SIA clusters were oriented along different $<111>$ directions intersecting at the precipitate centre. One of them entered the precipitate in $38 \mathrm{ps}$, the other in $1.1 \mathrm{~ns}$, resulting in a single $1 / 2<111>14$-SIA cluster. Thus, existence of an SIA cluster inside a precipitate does not preclude further cluster interaction and trapping. 


\subsection{MS calculations}

\subsubsection{Vacancy-precipitate interaction}

The interaction energy of a vacancy with a pure $\mathrm{Cu}$ precipitate of $1 \mathrm{~nm}$ radius was considered previously [22]. Figure 1 of that paper shows $E_{\mathrm{I}}$ as a function of the distance between the vacant site and precipitate centre along $<100>$ and $<111>$ directions. It has a minimum of between -0.5 and $-0.6 \mathrm{eV}$ for both directions when the vacancy is inside the precipitate $0.9 \mathrm{~nm}$ away from the centre. With increasing distance, $E_{\mathrm{I}}$ rises rapidly and is practically zero at $\sim 1.6 \mathrm{~nm}$ from the precipitate centre. (Similar results were obtained by Osetsky and Serra [27] with a long-range, non-equilibrium pair potential.) A vacancy-precipitate binding energy $E_{\mathrm{B}}$ $\left(=-E_{\mathrm{I}}\right)$ of $\sim 0.6 \mathrm{eV}$ implies that, under thermal ageing conditions, vacancies must spend significant time inside precipitates, where their fast diffusion [27] should lead to minimisation of the precipitate free energy, thereby resulting in equilibrium precipitate structure, i.e. $\sim 100$ at $\% \mathrm{Cu}$, in accordance with experimental observations.

\subsubsection{Interaction of an SIA cluster with single Cu atoms}

The interaction energy, $E_{\mathrm{I}}(r)$, of a 7-SIA cluster with a single $\mathrm{Cu}$ atom as a function of the distance, $r$, along the crowdion axis is shown in figure 2 . Three positions of the $\mathrm{Cu}$ atom are considered: a) inside the cluster glide prism in-line with the cluster centre, b) in the first atomic plane outside the glide prism at a site near the hexagon vertex, and c) in the first atomic plane outside the glide prism at a site along a hexagon side. Figure 2 shows that the SIA cluster is repelled $\left(E_{\mathrm{I}}>0\right)$ from the $\mathrm{Cu}$ atom in-line with its centre. The maximum energy is $0.14 \mathrm{eV}$, in agreement with the estimate from MD calculations using equation (1) in section 2.1. In the other two cases, the interaction is attractive, with $E_{\mathrm{I}}$ reaching a minimum of -0.05 to $-0.07 \mathrm{eV}$ at about $0.5 \mathrm{~nm}$ from the $\mathrm{Cu}$ atom. (The asymmetry of $E_{\mathrm{I}}(r)$ is due to asymmetry of the $<111>$ atomic rows through the cluster.) The maximum binding energy is again in agreement with that estimated from the MD simulations in section 3.1.

[Insert figure 2 about here]

\subsubsection{Interaction of an SIA cluster with Cu precipitates}


Figure 3 shows $E_{\mathrm{I}}(r)$ for the 7-SIA cluster and pure $\mathrm{Cu}$ precipitates with $R_{\mathrm{P}}$ ranging from 0.29 to $1.0 \mathrm{~nm}$ as a function of distance along [111] from the precipitate centre. The cluster centre is in-line with the precipitate centre. At large $r, E_{\mathrm{I}}$ is positive (repulsive). It increases with decreasing distance, but reaches a maximum at $r \sim 1.5-2.0 \mathrm{~nm}$ before decreasing and becoming negative. This is shown explicitly in figure 3 for $R_{\mathrm{P}} \leq 0.42 \mathrm{~nm}$ only. For larger precipitates, the complete curve could not be completed in this way because the cluster moved spontaneously during relaxation from its initial position into the precipitate.

[Insert figure 3 about here]

To obtain $E_{\mathrm{I}}$ in the region of instability arising from high energy gradient, a less accurate procedure was employed. The atomic system was relaxed but with the two central atoms of each crowdion prevented from moving from their relaxed arrangement in the pure $\mathrm{Fe}$ model. The accuracy of this procedure was verified by comparing $E_{\mathrm{I}}$ calculated by both methods where possible. An example of such a comparison is included in figure 4 for a precipitate of $0.55 \mathrm{~nm}$ radius. Close agreement is observed.

[Insert figure 4 about here]

Figure 5(a) shows the complete set of curves calculated in this way. At small separations there is attraction between cluster and precipitate, and $E_{\mathrm{I}}$ is as low as $-10 \mathrm{eV}$ in the centre of a $1 \mathrm{~nm}$ pure copper precipitate. Figure $5(\mathrm{~b})$ shows $E_{\mathrm{I}}$ normalised by the number of $\mathrm{Cu}$ atoms. It is independent of $R_{\mathrm{P}}$ at large $r$, but more repulsive in the region of the maximum ( $r=1.5-2 \mathrm{~nm})$ for small $R_{\mathrm{P}}$. We have also calculated $E_{\mathrm{I}}$ between a $1.0 \mathrm{~nm} \mathrm{Cu}$ precipitate and either a single crowdion or a cluster of three SIAs. Combined with the data above for the 7SIA cluster, $E_{\mathrm{I}}$ is found to scale with the number of SIAs in the repulsive region beyond $2 \mathrm{~nm}$. The reason for this behaviour is discussed in section 3.3 in the framework of elasticity theory.

[Insert figures 5(a) and 5(b) about here]

The results presented in figure 5(a) can be used to estimate the mean time for a cluster to penetrate inside a precipitate. Consider configuration 3 in figure 1: a 7-SIA cluster between two precipitates of $0.55 \mathrm{~nm}$ radius, simulated by MD and discussed in section 3.1. 
According to static calculations in figure 5(a), the barrier for penetration is $0.23 \mathrm{eV}$. Since at 4 $\mathrm{nm}$ distance from the precipitate, i.e. halfway between precipitates in the MD simulations, the interaction energy is $\sim 0.05 \mathrm{eV}$, twice this energy must be used as a reference state for the barrier estimates. Hence, the barrier in MD calculations was $\sim 0.13 \mathrm{eV}$. The mean time for penetration can be estimated roughly as $n \exp \left(0.13 \mathrm{eV} / \mathrm{k}_{\mathrm{B}} T\right) / v$, where $n$ is the number of (111) planes between the peak energy and the midpoint between precipitates, and $v \approx 10^{12} \mathrm{~s}^{-1}$ is the cluster jump frequency (see figure 6 in ref. [21]). For $n=10$ and $\mathrm{k}_{\mathrm{B}} T=0.05 \mathrm{eV}$ this yields $\sim 140 \mathrm{ps}$, which agrees well with the time of 230ps observed.

\subsubsection{Binding energy for SIAs and their clusters inside precipitates}

The binding energy for either a single crowdion or clusters of three or seven crowdions in the centre of a pure $\mathrm{Cu}$ precipitate was shown in figure 3 of ref. [22] for precipitates of different size. As seen above, $E_{\mathrm{B}}$ is a maximum in this region. For $R_{\mathrm{P}}=1 \mathrm{~nm}$, for example, it lies between 3 and $10 \mathrm{eV}$ for the 1- to 7-SIA defects; for $R_{\mathrm{P}}=0.6 \mathrm{~nm}$, it lies between 2 and $7 \mathrm{eV}$. Although $E_{\mathrm{B}}$ scales roughly with $R_{\mathrm{P}}$ for the precipitate size range considered, it becomes independent of $R_{\mathrm{P}}$ as size increases. It does not increase linearly with the number of interstitials, $N_{\mathrm{I}}$ : reasonable scaling with the square root of $N_{\mathrm{I}}$ is obtained, as shown in figure 6 , which contains an additional calculation for a 19 -SIA cluster in a $1 \mathrm{~nm}$ radius precipitate.

\section{[Insert figure 6 about here]}

These static relaxation calculations confirm the observation of the MD simulations presented in section 3.1 that strong binding exists between SIA clusters and $\mathrm{Cu}$ precipitates. The attraction seems at first sight to be in contradiction with the fact that copper is an oversized substitutional solute atom in bcc iron and does not bind to a single crowdion, and, similarly, a precipitate has a positive misfit and $E_{\mathrm{I}}(r)$ is positive at large $r$, as seen above. However, the energy for an SIA defect inside a precipitate is defined by $\mathrm{Cu}-\mathrm{Cu}$ bonds rather than $\mathrm{Fe}-\mathrm{Cu}$ or $\mathrm{Fe}-\mathrm{Fe}$ bonds. For the interatomic potential used, the cohesive energy of bec $\mathrm{Cu}$ is $0.89 \mathrm{eV}$ less than that of bcc $\mathrm{Fe}$ when both have the equilibrium lattice parameter of iron. Hence, the binding energy of an SIA defect to a precipitate arises from the difference in formation energy, $E^{\mathrm{f}}$, of the defect in bcc Fe and bcc $\mathrm{Cu}$. For example, for a single $<111>$ 
crowdion, $E^{\mathrm{f}}$ is $5 \mathrm{eV}$ in $\mathrm{Fe}$ for our model [23] and $2 \mathrm{eV}$ in a precipitate of $2.5 \mathrm{~nm}$ radius: the difference is consistent with the $E_{\mathrm{B}}$ value for $R_{\mathrm{P}}>0.8 \mathrm{~nm}$ shown in Fig. 6 .

\subsubsection{Interaction of SIA clusters with mixed Cu-Fe precipitates}

The effect of precipitate $\mathrm{Cu}$ concentration, $c_{\mathrm{Cu}}$, on $E_{\mathrm{I}}$ is shown in figure 7(a) for a 7-SIA loop outside a precipitate of $0.78 \mathrm{~nm}$ radius: $E_{\mathrm{I}}$ in this figure is normalised by $c_{\mathrm{Cu}}$. The constrained relaxation technique described in section 3.2.3 was used to estimate $E_{\mathrm{I}}$ for separations smaller than $2 \mathrm{~nm}$. It is seen that $E_{\mathrm{I}}$ decreases with decreasing $c_{\mathrm{Cu}}$ and scales linearly with it at sufficiently large separations $(>2.5-3 \mathrm{~nm}$ in the case considered in the figure).

Figure 7(b) shows $E_{\mathrm{B}}$, normalised by $c_{\mathrm{Cu}}{ }^{2}$, for the 7-SIA cluster inside precipitates of different size and with $\mathrm{Cu}$ concentration from 25 to $100 \mathrm{at} \%$. The total binding is stronger at higher $c_{\mathrm{Cu}}$ and is proportional to $R_{\mathrm{P}}$, as for pure $\mathrm{Cu}$ precipitates. Also, for precipitates with $c_{\mathrm{Cu}}$ of $50 \mathrm{at} \%$ and higher, $E_{\mathrm{B}}$ scales approximately with $c_{\mathrm{Cu}}{ }^{2}$, that is the number of $\mathrm{Cu}-\mathrm{Cu}$ bonds. More exact scaling should take into consideration the existence of $\mathrm{Fe}-\mathrm{Cu}$ bonds, which are repulsive, as manifested in positive substitution energy of $\mathrm{Cu}$ atoms in bcc iron $(\sim 1$ $\mathrm{eV}$ for the potential set used). For the lowest $\mathrm{Cu}$ concentration considered (25at\%), the radius dependence exhibits more irregular behaviour compared to those at higher concentrations. This is probably due to fluctuations in spatial arrangement of $\mathrm{Cu}$ atoms inside precipitates, since only one particular arrangement was calculated in each case. Averaging over different configurations should result in smoothing of the curves.

[Insert figures 7(a) and 7(b) about here]

\subsubsection{SIA clusters on $<111>$ axes not passing through the precipitate centre}

The SIA clusters treated above have centres positioned on the [111] atomic rows containing the centre atom of the near-spherical precipitate. In this section, clusters on [111] rows offprecipitate-centre are considered. Figure 8(a) presents an example for a pure $\mathrm{Cu}$ precipitate of $1 \mathrm{~nm}$ radius and a 7-SIA loop with central [111] crowdion axis shifted by various distances along [11 $\overline{2}$ ] from the precipitate centre. Beyond the distance of $1.4 \mathrm{~nm}$, the cluster glide prism does not intersect the precipitate. The minimum $E_{\mathrm{I}}$ occurs at zero distance along [111], i.e. on the (111) plane through the precipitate centre, and, although decreasing with increasing 


\subsubsection{Single SIA-precipitate interaction}

Figure 9 compares the interaction of an SIA in either dumbbell or crowdion configuration with a pure $\mathrm{Cu}$ precipitate of $1 \mathrm{~nm}$ radius. The two non-equivalent orientations for each defect are considered. The constrained relaxation method described above was employed and gives the same energy as complete relaxation for all configurations when $r$ is larger than $3.5 \mathrm{~nm}$. The [111] crowdion has the highest peak (of $0.13 \mathrm{eV}$ ) in $E_{\mathrm{I}}$. This is because its displacements are collinear with those from the precipitate. The low maximum $(\sim 0.003 \mathrm{eV})$ of the $[11 \overline{1}]$ crowdion arises because of the $70^{\circ}$ angle between the crowdion axis and the radial displacements of the precipitate. (Note that, in the framework of the model treating the crowdion as a small dislocation loop, $E_{\mathrm{I}}$ decreases to zero when the angle approaches $90^{\circ}$.) The values of the peak in $E_{\mathrm{I}}$ for the [1 $\overline{10}$ ] and [110] dumbbells are 0.016 and $0.002 \mathrm{eV}$, and are small because of more symmetrical and localised displacement field. Crowdions at the centre of the precipitate have binding energy of $2.96 \mathrm{eV}$, irrespective of the $<111>$ orientation. The [110] dumbbell has $E_{\mathrm{B}}$ smaller than that of crowdion by $0.76 \mathrm{eV}$. These results imply that under electron irradiation, when damage is produced in the form of Frenkel pairs and single interstitials migrate in dumbbell configuration, $\mathrm{Cu}$ precipitates should act as strong recombination regions for both vacancies and SIAs.

[Insert figure 9 about here]

\subsection{Elasticity theory results}

Figure 10 shows the interaction energy for a 7-SIA cluster and a pure $\mathrm{Cu}$ precipitate of $1 \mathrm{~nm}$ radius calculated by MS and using equations (4) and (5). The interaction energy described by 
equation (4) is shown by empty squares. For these calculations, the misfit parameter, $\varepsilon$, was taken to be equal to 0.022, as obtained by Harry and Bacon [29] using the same potential as in our calculations. This value gives a good fit of equations (2) and (3) to the displacement field within and around the precipitate obtained in MS calculations. Also, we used $G_{\mathrm{m}}=89.2 \mathrm{GPa}$ as given by the potential set used, $b=\sqrt{3} a_{0} / 2$ and $A=N_{\mathrm{I}} a_{0}^{2} / \sqrt{3}$ for the area of the loop of $N_{\text {I }}$ crowdions. As seen from the figure, equation (5) gives the form of the repulsive interaction at large separation found in MD and MS calculations described earlier. In particular, it explains the proportionality of $E_{\mathrm{I}}$ to the number of $\mathrm{Cu}$ atoms in a precipitate shown in figures 5(b) and 7(a). Indeed, in equation (4) the interaction energy is proportional to the volume of inclusion and the area of the loop.

[Insert figure 10 about here]

The interaction energy due to modulus difference between matrix and inclusion given by equation (5) is shown in figure 10 by empty circles and is attractive. It was calculated with $v_{\mathrm{m}}=0.293$ (Table 15.1 in [30]) and $c=A b / 4 \pi$, i.e. the misfit volume of the 'spherical' defect representing the loop is taken to be the volume $A b$ of the interstitial atoms constituting the loop. For the shear modulus of bcc $\mathrm{Cu}$ precipitate, $G_{\mathrm{P}}=\mathrm{C}_{44}-\left(2 \mathrm{C}_{44}+\mathrm{C}_{12}-\mathrm{C}_{11}\right) / 5$, we calculated the elastic constants $\mathrm{C}_{11}, \mathrm{C}_{12}, \mathrm{C}_{44}$ as a function the lattice parameter, see figure 11 , and take the value $G_{\mathrm{P}}=82.4 \mathrm{GPa}$, corresponding to the lattice parameter $0.293 \mathrm{~nm}$ of large $\mathrm{Cu}$ precipitates $\left(R_{\mathrm{P}} \geq 2 \mathrm{~nm}\right)$. Note the change in the behaviour of elastic moduli of bcc $\mathrm{Cu}$ at the lattice parameter of about $0.295 \mathrm{~nm}$. This feature corresponds to dramatic evolution of the dispersion relation with lattice parameter change [23].

[Insert figure 11(a) and 11(b) about here]

As seen from figure 10, equation (5) describes attraction between precipitates and SIA defects at small separations outside the precipitate, as observed in MS calculations presented in section 3.2. Equation (5) indicates that the dependence of the interaction energy on precipitate size, i.e. number of $\mathrm{Cu}$ atoms in a precipitate, and the number of SIAs in the loop is more complicated in this case.

The sum of the interaction energies calculated using equations (4) and (5) is shown in figure 10 by filled circles. The dependence of the energy on the distance is qualitatively 


\section{Implications and conclusions}

The simulations described above confirm significant binding between a vacancy and a copper precipitate. This implies that, under thermal ageing conditions, vacancies must spend significant time inside precipitates, where their fast diffusion [27] should lead to minimisation of the precipitate free energy and result in equilibrium precipitate structure, i.e. $\sim 100 \mathrm{at} \% \mathrm{Cu}$, in accordance with experimental observations.

The results also imply that the production of interstitial defects in $\mathrm{Fe}-\mathrm{Cu}$ alloys under irradiation must affect copper precipitation kinetics in a more complicated way than a simple rescaling of the timescale. The simulations show that single SIAs and SIA clusters created by irradiation can become trapped near and inside precipitates. The interpretation and explanation of this phenomenon in the framework of elasticity theory indicate that it is not an artefact but, on the contrary, must be of general nature. Note also that MD modelling shows attraction of an edge dislocation to $\mathrm{Cu}$ precipitates [31], which may be considered as the limiting case of an SIA cluster of infinitely large radius.

It follows from the calculations that single interstitials migrating as $<110>$ dumbbells encounter a small energy barrier to enter a precipitate, e.g. $\sim 0.03 \mathrm{eV}$ for a $1 \mathrm{~nm}$ radius pure $\mathrm{Cu}$ precipitate, which is smaller or comparable with thermal energy $(\sim 0.05 \mathrm{eV})$ at temperatures of interest. This implies that the interaction frequency of single SIAs with the precipitates must be similar to that of vacancies, since both defects execute three-dimensional random walk. Thus, under electron irradiation conditions, precipitates may act as recombination regions for the both types of point defect. This should result in decreasing rate of precipitate growth, but should not prevent growth completely, for the interaction frequency of SIAs with precipitates should be smaller than that of vacancies. There are two reasons for this. First, there is a small but non-zero barrier for SIA-precipitate interaction, mentioned above. Second, single SIAs have bigger cross-section for interaction with dislocations than vacancies, usually described in terms of the dislocation bias factor, $B_{\mathrm{dis}} \sim 0.03$ [32], a parameter that enters the theory of void swelling in materials under irradiation. Hence, even if we neglect the existence of the energy barrier for SIA-precipitate interaction, there should be an excess of vacancies interacting with 
precipitates, which should limit the decrease of precipitate growth rate due to interstitials to the maximum of the factor of $B_{\text {dis. }}$.

Under neutron irradiation production and accumulation of a significant number density of SIA clusters occurs. These clusters may become trapped between, inside or in the vicinity of precipitates. SIA clusters trapped between precipitates should recombine with vacancies, thus decreasing vacancy concentration and slowing down the precipitation kinetics. Precipitates with SIA clusters trapped inside or nearby should act effectively as unsaturable sinks for vacancies, and this would suppress evaporation of copper atoms from precipitates and, hence, precipitate coarsening. We conclude that the effect on precipitate evolution must be different from that under electron irradiation, for two reasons. First, since SIA clusters migrate one-dimensionally, the cross-section of their interaction with precipitates is proportional to the radius squared of the precipitate, in contrast to the radius dependence for three-dimensionally migrating vacancies and single interstitial atoms. This should result in increased stability of large precipitates, for the net flux of vacancies, and hence $\mathrm{Cu}$ atoms from them would be relatively smaller. Second, unlike for single SIAs, the energy barrier for SIA clusters to enter a precipitate increases strongly with increasing precipitate size. This must result in an increase of stability of small precipitates with respect to the larger ones. It is therefore predicted that the combined effect of cross-section and energy barrier may result in the relative stability of precipitates of some particular size, for the net flux of $\mathrm{Cu}$ atoms from precipitates larger or smaller than this would be higher. This may be the reason for observation of the absence of precipitate growth under neutron irradiation conditions.

Furthermore, entrapment of SIA clusters should have an effect on the precipitate structure. Indeed, vacancy jumps in the vicinity of an SIA cluster trapped inside or near a precipitate should be governed by strong vacancy interaction with the cluster rather than between vacancy and copper atoms. So, the free energy of precipitates would not be minimised. This can explain mixed $\mathrm{Cu}-\mathrm{Fe}$ structure of precipitates observed under neutron irradiation conditions. In addition, significant lattice distortions due to trapped SIAs could help transformation of a precipitate towards fcc structure. This may be the reason for the HREM observation of the smaller minimum size, 2 to $4 \mathrm{~nm}$, of transformed precipitates in neutron-irradiated alloys [33].

The scenario described may not be complete, however, and should include clustering of vacancies as well as SIAs. Indeed, it follows from positron annihilation experiments by Nagai et al. [34] that there is probably association of vacancy clusters and precipitates in 
neutron-irradiated steels. A full account of the effects described above in precipitate evolution under different conditions will be the subject of a future publication.

Finally, as a general remark, we note that although we have studied the $\mathrm{Fe}-\mathrm{Cu}$ system, the results should have wider application. Namely, both vacancy and interstitial defects may be strongly bound to precipitates with weaker cohesion than the matrix. This effect may have consequences for the design of radiation-resistant alloys.

\section{Acknowledgments}

A.C.A. would like to thank the University of Liverpool for providing a studentship grant. This work was performed under a research grant from the UK Engineering and Physical Sciences Research Council and partly supported by the Division of Materials Sciences and Engineering and the Office of Fusion Energy Sciences, U.S. Department of Energy, under contract DE-AC05-00OR22725 with UT-Battelle, LLC. We thank Dr Ian C. Smith of the CSD department for the provision of computing resources of the University's experimental Condor service. 


\section{References}

[1] G. R. Odette and G. E. Lucas, 2001, JMMMS 53, N7, pp. 18-22.

[2] S. B. Fisher, J. E. Harbottle and N. Aldrige, Phil. Trans. R. Soc. Lond. A 31530 (1985).

[3] P. Auger, P. Pareige, M. Akamatsu, et al., J. Nucl. Mater. 225225 (1995).

[4] J. T. Buswell, C. A. English, M. G. Hetherington, et al., in Effects of Radiation on Materials, ASTM STP 104611127 (1990).

[5] M. H. Mathon, A. Barbu, F. Dunstetter, et al., J. Nucl. Mater. 245224 (1997).

[6] R. Monzen, M. L. Jenkins and A. P. Sutton, Phil. Mag. A 80711 (2000).

[7] T. Harry and D. J. Bacon, Acta Mater. 50209 (2002).

[8] M. E. Fine and D. Isheim, Scripta Mater. 53115 (2005).

[9] H. A. Hardouin Duparc, R. C. Doole, M. L. Jenkins, et al., Phil. Mag. Lett. 71325 (1995).

[10] T. N. Lê, A. Barbu, D. Liu, et al., Scripta Metall. Mater. 26771 (1992).

[11] A. C. Nicol, M. L. Jenkins and M. A. Kirk, Mat. Res. Soc. Symp. Proc. 540409 (1999).

[12] J. T. Buswell, P. J. E. Bischler, S. T. Fenton, et al., J. Nucl. Mater. 205198 (1993).

[13] R. B. Jones and C. J. Bolton, Proc. $24^{\text {th }}$ Water Reactor Safety Meeting, Bethesda, Maryland, USA, October 1996 (USNRC, NUREG/CP-0157, vol. 2 1997), pp. 25-48.

[14] P. Auger, P. Pareige, S. Welzel, et al., J. Nucl. Mater. 280331 (2000).

[15] S. I. Golubov, A. Serra, Yu. N. Osetsky, et al., J. Nucl. Mater. 277113 (2000).

[16] Y. Le Bouar and F. Soisson, Phys. Rev. B 65094103 (2002).

[17] A. V. Barashev, S. I. Golubov, D. J. Bacon, et al., Acta Mater. 52877 (2004).

[18] F. Christien and A. Barbu, J. Nucl. Mater. 32490 (2004).

[19] A.V. Barashev and A. C. Arokiam, Phil. Mag. Lett. 86321 (2006).

[20] D. J. Bacon, F. Gao and Yu. N. Osetsky, J. Nucl. Mater. 2761 (2000).

[21] Yu. N. Osetsky, D. J. Bacon, A. Serra, et al., Phil. Mag. A 8361 (2003).

[22] A. C. Arokiam, A. V. Barashev, D. J. Bacon, et al., Phil. Mag. Lett. 85491 (2005).

[23] G. J. Ackland, D. J. Bacon, A. F. Calder, et al., Phil. Mag. A 75713 (1997).

[24] Yu. N. Osetsky, A. G. Mikhin and A. Serra, Phil. Mag. A 72361 (1995).

[25] D. Frenkel and B. Smit, Understanding Molecular Simulations: From Algorithms to Applications (Academic Press, California, 1996), pp. 61-67.

[26] Yu. N. Osetsky,_Defect and Diffusion Forum 188-190 71 (2001).

[27] Yu. N. Osetsky, A. Serra, Phil. Mag. A 73249 (1996); 751097 (1997).

[28] F. C. Moon and Y. Pao, J. Appl. Phys. 38595 (1967). 
[29] T. Harry and D. J. Bacon, Acta Mater. 50195 (2002).

[30] E. A. Brandes (Editor), Smithells Metals Reference Book, sixth edition (Butterworth, London, 1983).

[31] Yu. N. Osetsky, D. J. Bacon and V. Mohles, Philos. Mag. 833623 (2003).

[32] P. T. Heald, Phil. Mag. 31551 (1975).

[33] A. C. Nicol, M. L. Jenkins and M. A. Kirk, Mat. Res. Soc. Symp. Proc. 540409 (1999).

[34] Y. Nagai, Z. Tang, M. Hassegawa, et al., Phys. Rev. B 63134110 (2001). 


\section{Figure captions}

Figure 1. Fraction of time spent by a 7-SIA cluster in different (111) planes when migrating along [111] between: (1) $\mathrm{Cu}$ atoms on the [111] line through the cluster centre at $T=600 \mathrm{~K}$; (2) $\mathrm{Cu}$ atoms on the [111] line just outside the cluster glide cylinder at $T=300 \mathrm{~K}$; and (3) Cu precipitates of $0.55 \mathrm{~nm}$ radius centred on the [111] line through the cluster centre at $T=600 \mathrm{~K}$.

Figure 2. $\quad E_{\mathrm{I}}$ of a 7-SIA cluster with isolated $\mathrm{Cu}$ atoms versus distance along the [111] direction of the cluster Burgers vector.

Figure 3. $\quad E_{\mathrm{I}}$ versus distance from precipitate centre along [111] for a 7-SIA cluster and spherical precipitates of pure $\mathrm{Cu}$ with different radii.

Figure 4. $\quad E_{\mathrm{I}}$ versus distance from precipitate centre along [111] for a 7-SIA cluster and a $\mathrm{Cu}$ precipitate of $0.55 \mathrm{~nm}$ radius, calculated for either complete or constrained relaxation.

Figure 5. $\quad E_{\mathrm{I}}$ versus distance from precipitate centre along [111] for a 7-SIA cluster and $\mathrm{Cu}$ precipitates of different radii, calculated for either complete or constrained relaxation. (a) Total energy. (b) Energy divided by the number of $\mathrm{Cu}$ atoms in a precipitate.

Figure 6. $\quad E_{\mathrm{I}}$ versus precipitate radius for a crowdion and 3-, 7- and 19-SIA loops when the SIA defect is inside a pure $\mathrm{Cu}$ precipitate. The energy is divided by the square root of the number of SIAs in each case.

Figure 7. $\quad E_{\mathrm{I}}$ of a 7-SIA cluster with precipitates having different $\mathrm{Cu}$ concentration, $c_{\mathrm{Cu}}$. (a) Energy divided by $c_{\mathrm{Cu}}$ versus distance from precipitate centre along [111] for a precipitate of $0.78 \mathrm{~nm}$ radius. (b) Energy divided by $c_{\mathrm{Cu}}{ }^{2}$ versus precipitate radius when the cluster is inside the precipitate. 
Figure 8. $\quad E_{\mathrm{I}}$ versus distance along [111] for a 7-SIA cluster and a 1nm-radius $\mathrm{Cu}$ precipitate when the central axis of the cluster is offset from the precipitate centre along either (a) $[11 \overline{2}]$ or (b) $\left[\begin{array}{lll}1 & 1 & 0\end{array}\right]$.

Figure 9. $\quad E_{\mathrm{I}}$ versus distance from precipitate centre along [111] for an SIA in either dumbbell or crowdion configuration with a $\mathrm{Cu}$ precipitate of $1 \mathrm{~nm}$ radius.

Figure 10. Comparison of $E_{\mathrm{I}}$ versus distance along [111] from precipitate centre for a 7-SIA cluster and a $\mathrm{Cu}$ precipitate of $1 \mathrm{~nm}$ radius obtained from MS (filled squares), equation (4) for a misfitting inclusion and a loop (empty squares), and equation (5) for an inclusion with different shear modulus from the matrix and the loop treated as a spherical defect (empty circles). The sum of equations (4) and (5) is shown by filled circles.

Figure 11. Elastic moduli as a function of lattice parameter. (a) bcc $\mathrm{Cu}$. The arrow shows the shear modulus corresponding to the lattice parameter $0.293 \mathrm{~nm}$ of a large $\mathrm{Cu}$ precipitate $\left(R_{\mathrm{P}} \geq 2 \mathrm{~nm}\right)$. (b) bcc Fe. 


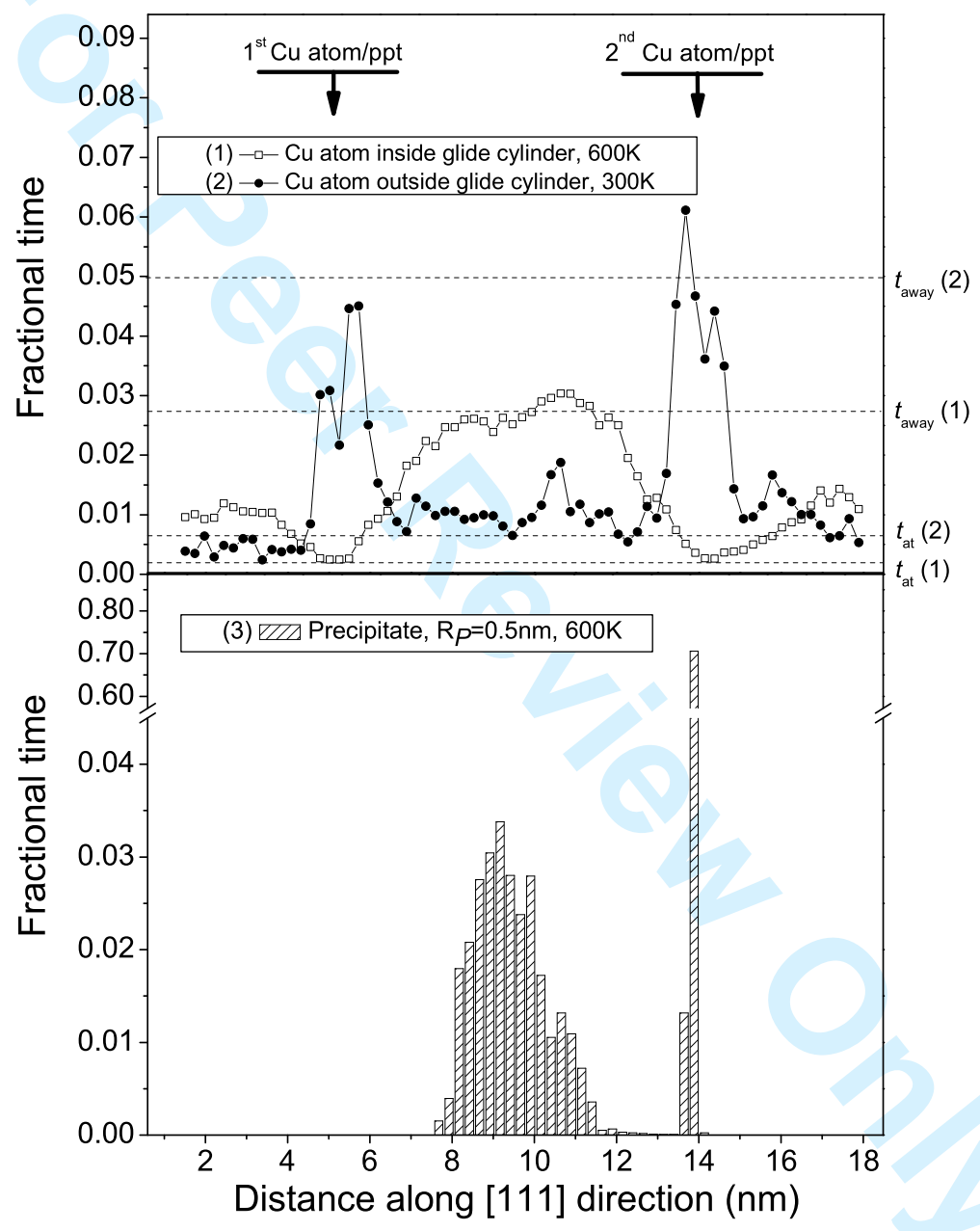




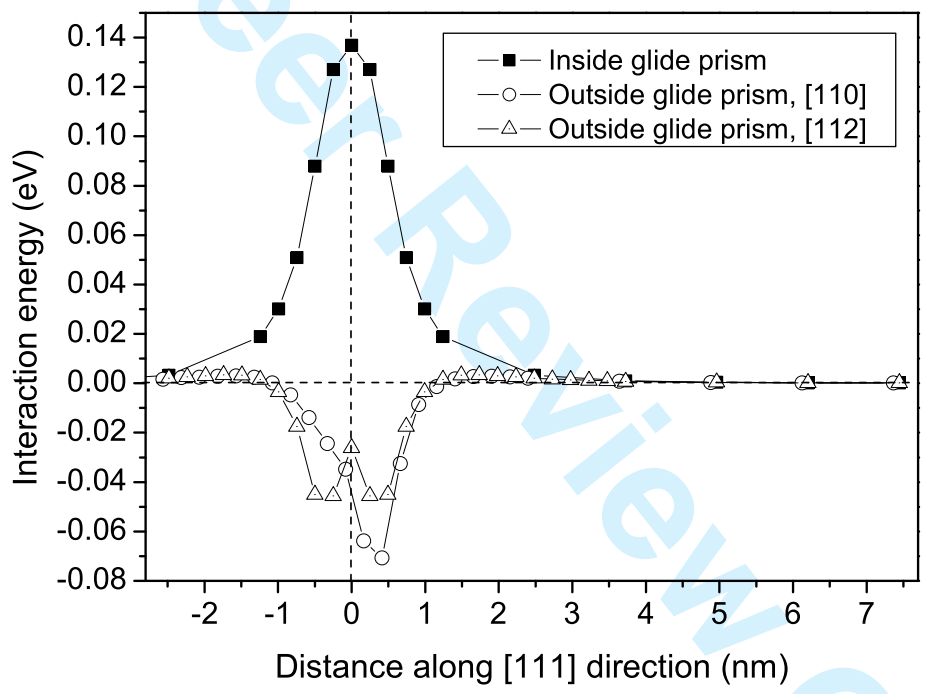




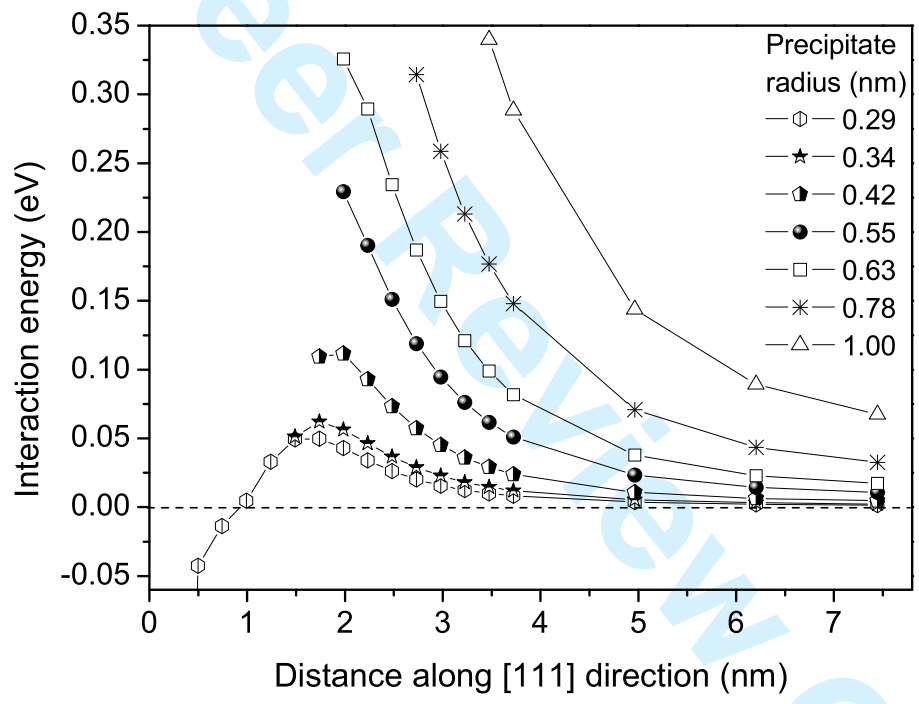

http://mc.manuscriptcentral.com/pm-pml 


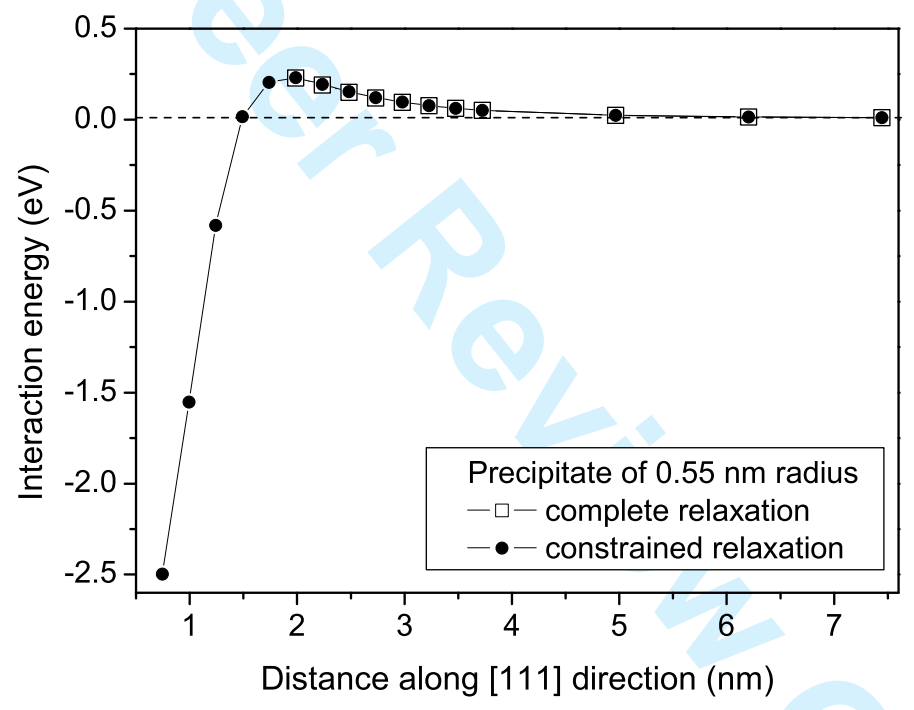




1
2
3
4
5
6
7
8
9
10
11
12
13
14
15
16
17
18
19
20
21
22
23
24
25
26
27
28
29
30
31
32
33
34
35
36
37
38
39
40
41
42
43
44
45
46
47
48
49
50
51
52
53
54
55
56
57
58
59
60

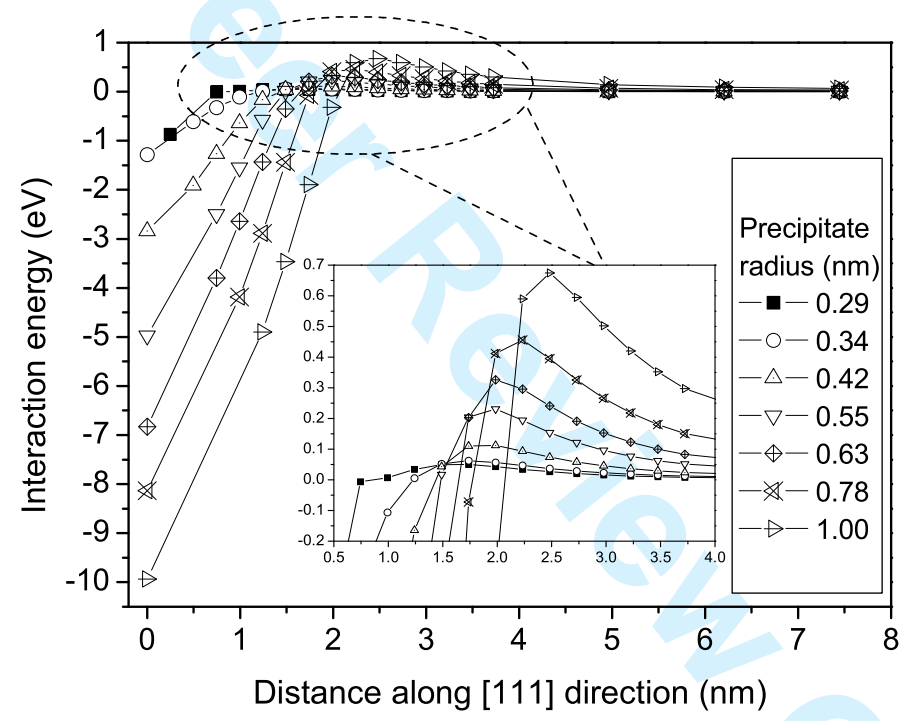

http://mc.manuscriptcentral.com/pm-pml 


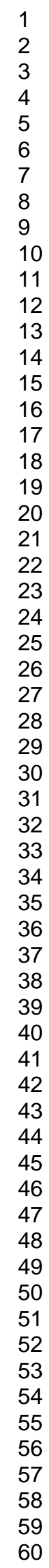

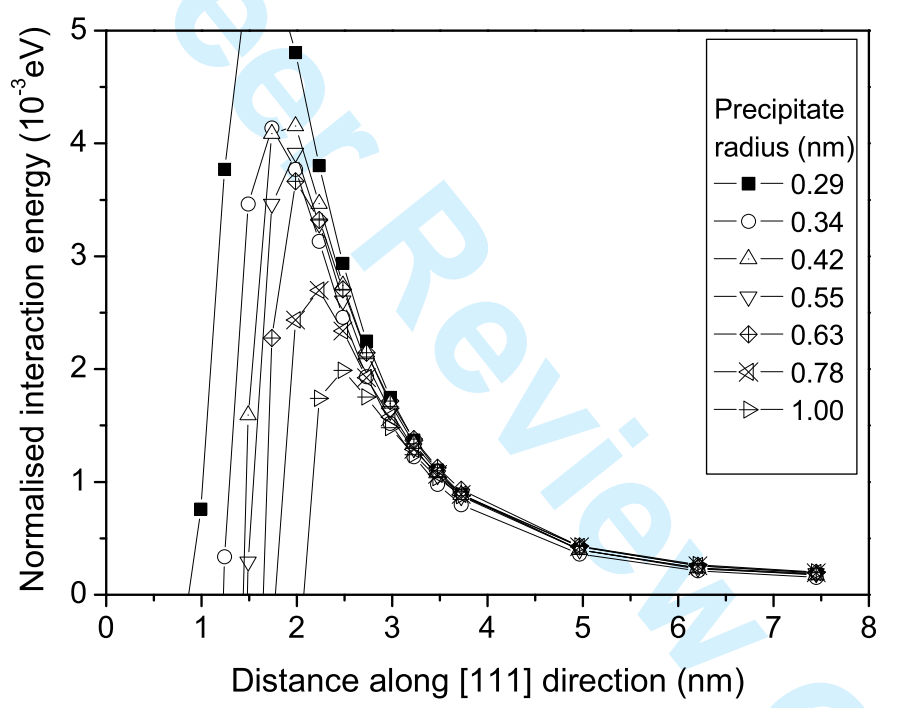

http://mc.manuscriptcentral.com/pm-pml 


1
2
3
4
5
6
7
8
9
10
11
12
13
14
15
16
17
18
19
20
21
22
23
24
25
26
27
28
29
30
31
32
33
34
35
36
37
38
39
40
41
42
43
44
45
46
47
48
49
50
51
52
53
54
55
56
57
59
60

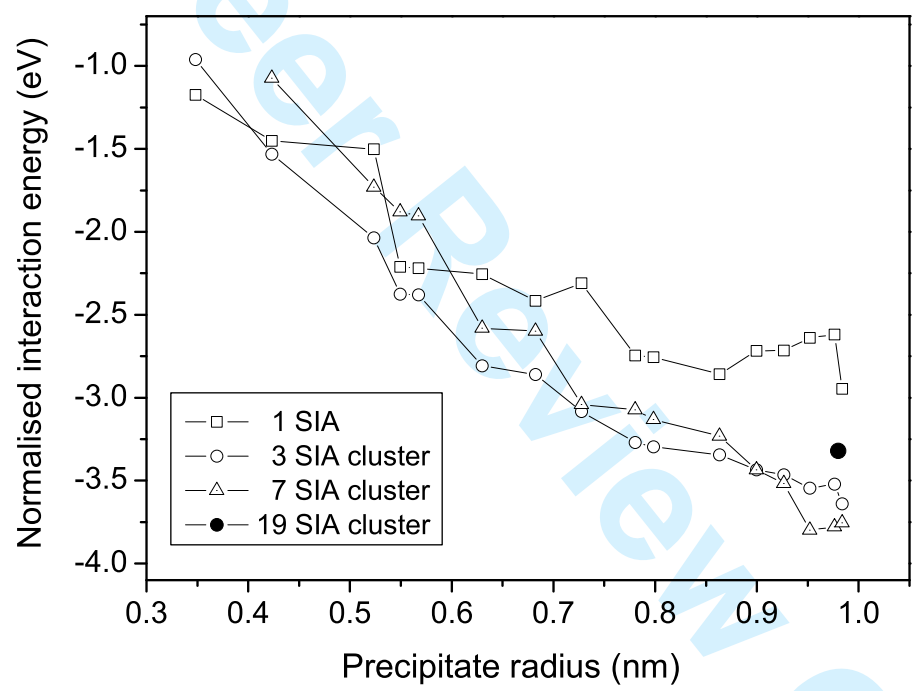

http://mc.manuscriptcentral.com/pm-pml 


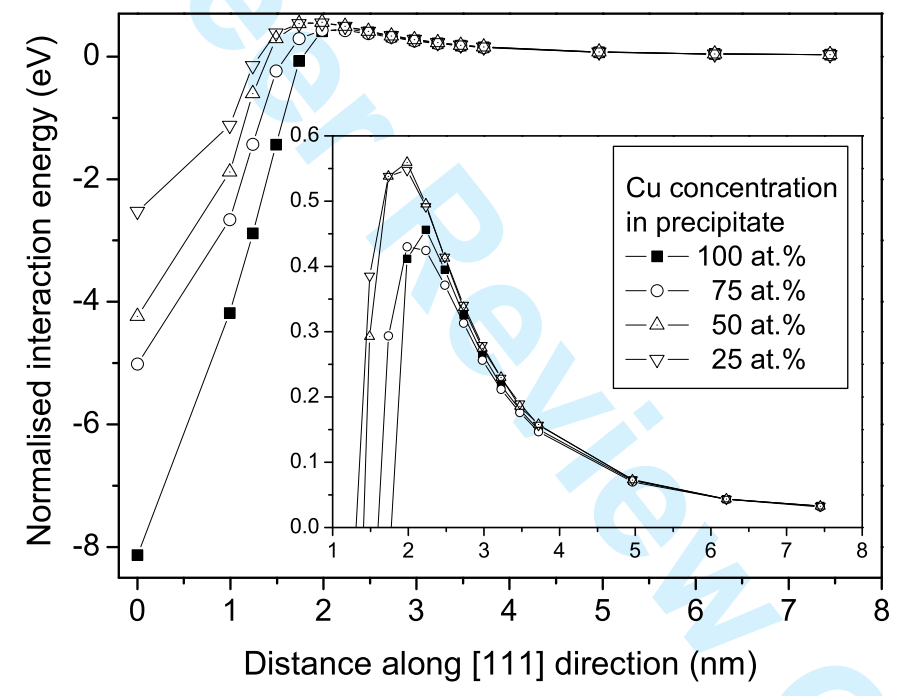




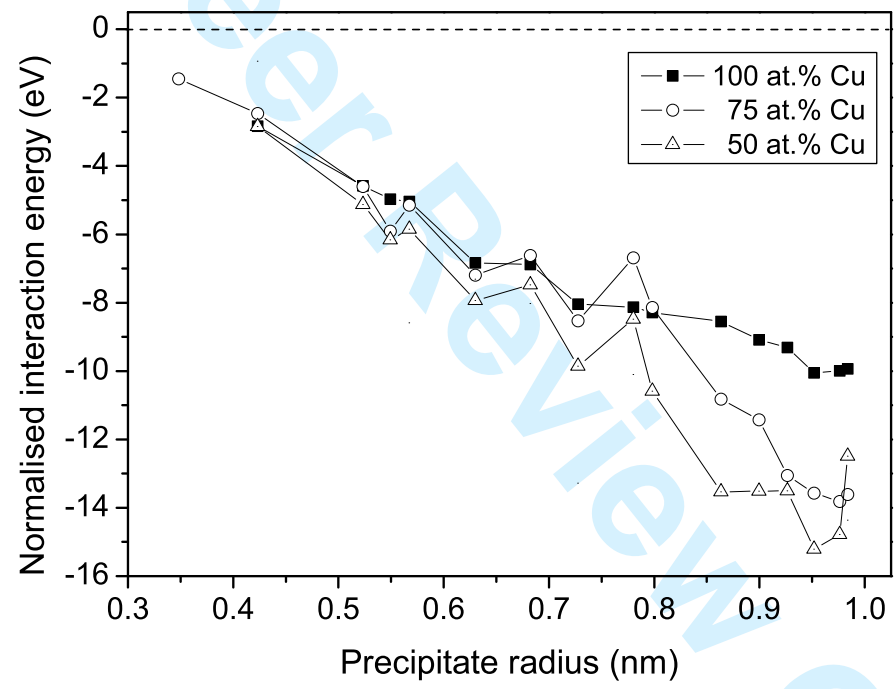

http://mc.manuscriptcentral.com/pm-pml 


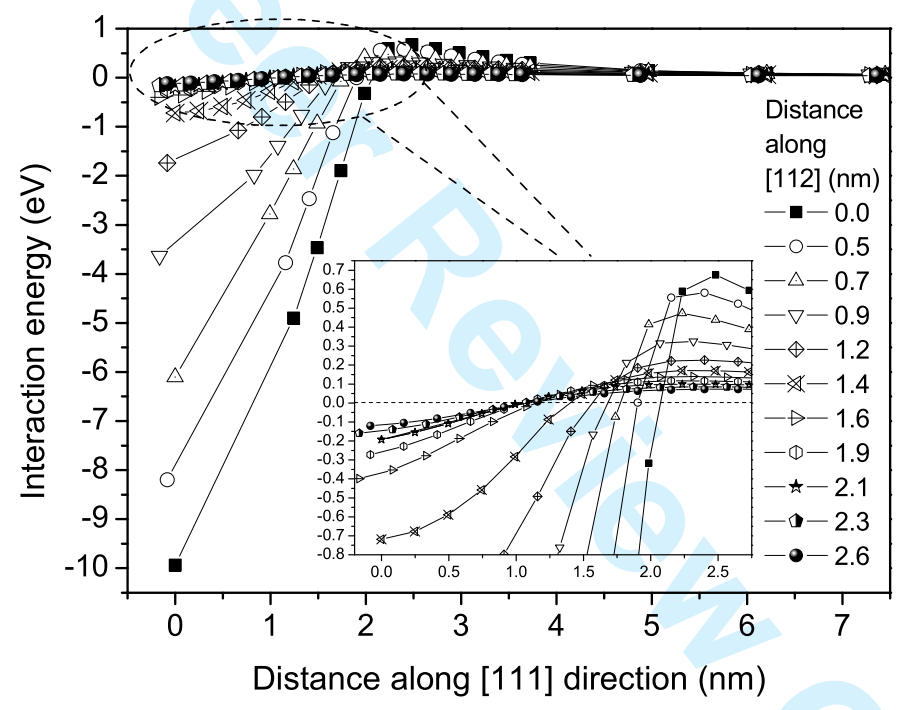

http://mc.manuscriptcentral.com/pm-pml 


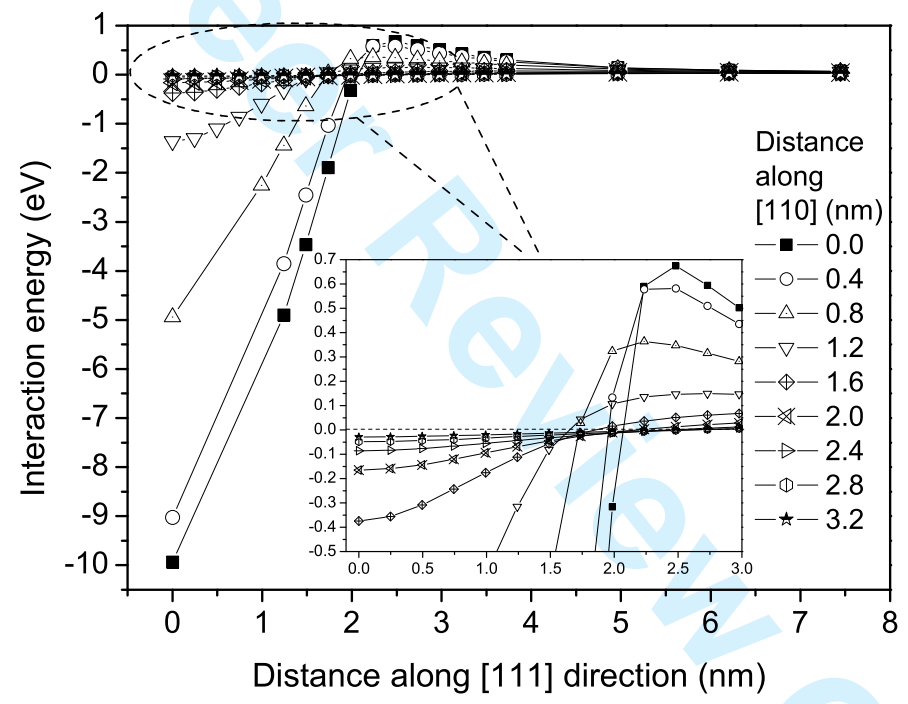

http://mc.manuscriptcentral.com/pm-pml 


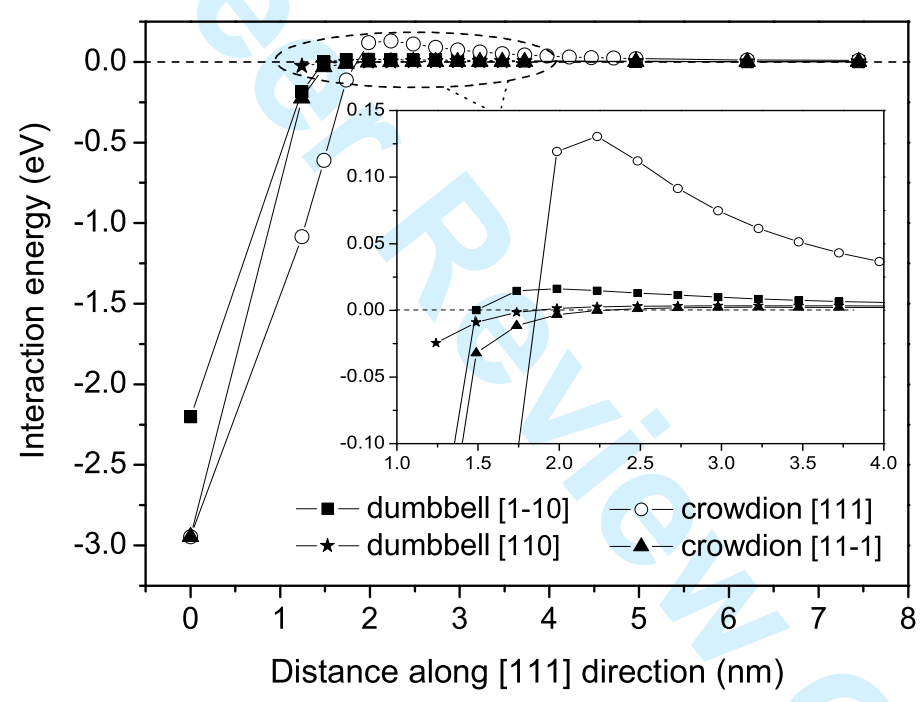




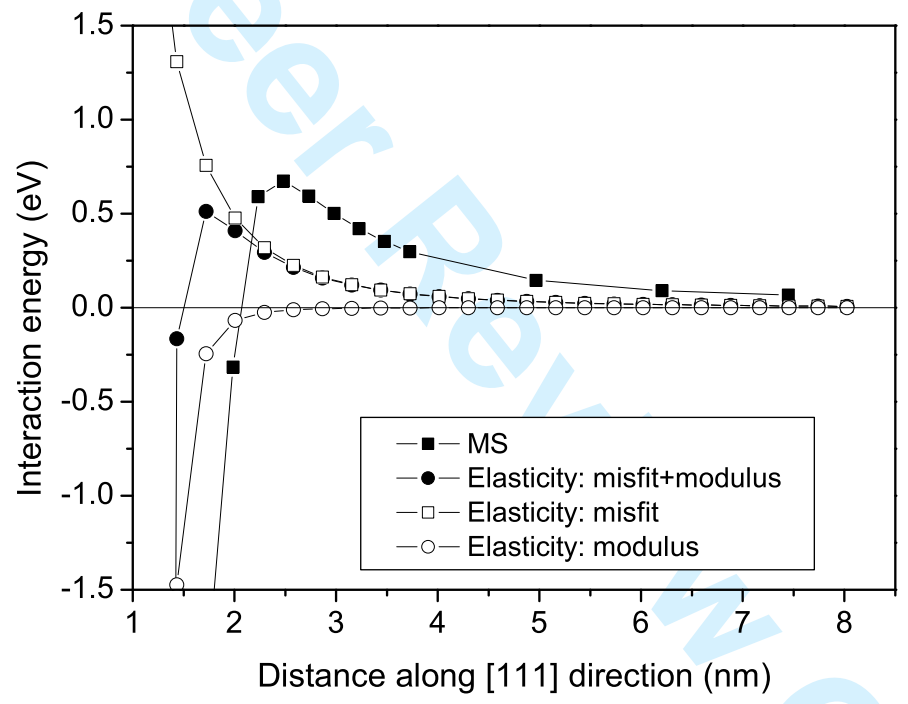

http://mc.manuscriptcentral.com/pm-pml 


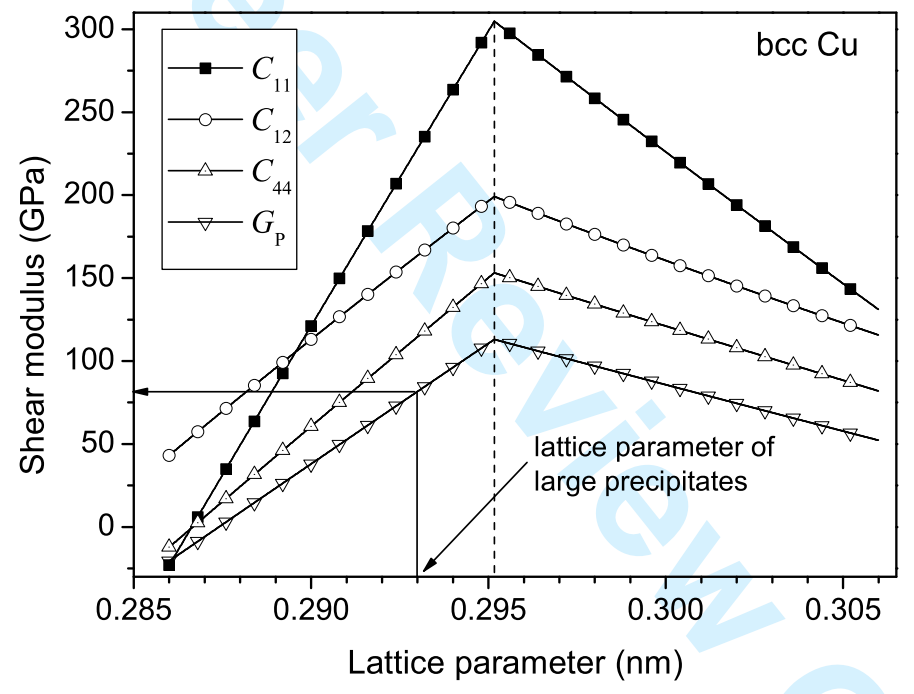




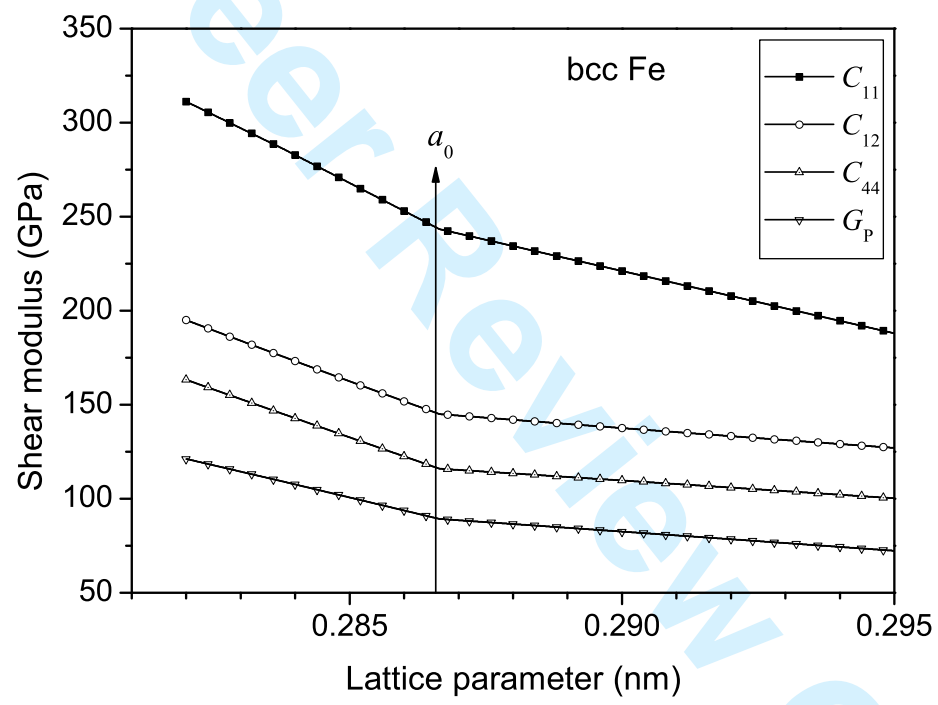

http://mc.manuscriptcentral.com/pm-pml 